\title{
"e-Praja Suwa Arunalu": A Pilot Study of a Health Information Management System for Public Health Midwives in Sri Lanka
}

\author{
Dr. E. Shan S. Rodrigo MBBS, MSc \\ Medical Officer (Health Informatics), National Programme for Tuberculosis Control and Chest Diseases \\ Ministry of Health, Sri Lanka \\ E-Mail address: semuthurodrigo@gmail.com
}

Dr. Samantha R. U. Wimalaratne BDS, MSc, MD

Director Health Information, Ministry of Health, Sri Lanka

E-Mail address: sru_wimalaratne@yahoo.com

\author{
Dr. Rohan B. Marasinghe MBBs, $\mathrm{PhD}$ \\ Senior Lecturer, Department of Medical Education and Health Sciences, Faculty of Medical Sciences \\ University of Sri Jayewardenepura, Sri Lanka \\ E-Mail address: rohanabm@yahoo.com
}

Prof. Sisira Edirippulige GradCert in Higher Ed, MSc, $\mathrm{PhD}, \mathrm{PhD}$

Lecturer / Coordinator - Postgraduate Programmes in e-Healthcare, Centre for Online Health, University of Queensland, Australia

E-Mail address: s.edirippulige@uq.edu.au

Sri Lanka Journal of Bio-Medical informatics 2012;3(2):40-46

doi: http://dx.doi.org/10.4038/sljbmi.v3i2.4737

\begin{abstract}
We conducted a needs analysis amongst 16 Public Health Midwives (PHMs) in Sri Lanka and found that they spend most of their time on managing health records. We developed an electronic Health Information Management System (HIMS) to help them with their work. The HIMS was designed so that it could accept data from the PHMs, and generate reports which could be used by the PHMs themselves as well as by their supervisors. The HIMS was tested by a group of 16 PHMs in a remote area in the Rathnapura district. Minilaptops with the software were distributed to the PHMs and they were given the necessary training. They started entering historical data from the registers into the system by themselves. Nearly 10,000 public health records were generated in the first three months. In a subsequent survey, all the PHMs gave positive answers indicating that they were happy with the pilot project and that they would like to continue using it to enhance their service. The system seems to be a practical solution for the field activities of PHMs in Sri Lanka. The knowledge gained from this study would be useful for future e-Health implementations in the public health sector of Sri Lanka.
\end{abstract}

Keywords - Health Information Management System; Public Health Midwives; e-Health

\section{Introduction}

Public health is an information-intensive field and depends on health related information regarding the community. Effective public health practice requires timely, accurate and authoritative information from a variety of sources ${ }^{(1)}$. The success of preventive health care depends on the awareness of health related matters in the community, taking appropriate steps to deal with the problems combined with follow-up ${ }^{(2,3,4)}$. Such steps are best taken at grass roots level where the public health field workers are involved. In Sri Lanka, such health workers are deployed under a Medical Officer of Health (MOH) who is responsible for providing preventive health care in particular catchment areas ${ }^{(5,6)}$. Most of the final statistics related to public health at central level is regenerated from data provided by these field workers via the $\mathrm{MOH}$. Thus utilising an information management system at $\mathrm{MOH}$ level in 
order to enhance the public health field services would improve the health service of Sri Lanka.

PHMs are the 'front line' health care providers responsible for provision of maternal and child health, and family planning services at the community level in Sri Lanka ${ }^{(5,7)}$. Their duties include providing ante-natal, post-natal, child health, and well women care as well as family planning. PHMs mainly provide preventive care but may also need to provide simple curative care especially in remote areas. Simultaneously, they perform clerical duties which include documentation of public health data and its maintenance. Documentation is done manually and is paper based. The PHM is required to communicate summarised data (registers and records) to respective regional and central levels. Several recent studies have revealed that PHMs devote considerable time to preparing such data, which in turn has affected the quality of their services badly ${ }^{(5,7)}$. Therefore, introducing a solution for public health data management at grass roots level is essential.

We have therefore launched a pilot project called "e-Praja Suwa Arunalu" among a selected group of PHMs in a remote $\mathrm{MOH}$ area. The project implemented a computerised public health information system for storing and manipulating the data related to the activities of midwives and the data of residents receiving care from PHMs. In addition, the HIMS stores maps of the area and provides the facility to mark index cases in maternal and child health activities.

\section{Objectives}

The objective was to develop an electronic HIMS which is acceptable to the PHMs of Sri Lanka. The specific objectives were:

- To carry out a situation analysis of existing information systems related to the public health activities of PHMs.

- To develop an appropriate computer based system to manage public health related information at the PHM level.

- To improve the capacity of PHMs in using computerised information systems.

- To test the feasibility of using the computerised HIMS at the field level.

\section{The following benefits were envisaged for the PHMs}

- $\quad$ Reducing work load and enhancing the quality of the service provided.

- Increasing the quality of data.

- Identifying health problems which may lead to preventive healthcare activities at the community level in remote areas.

- Helping and guiding them in daily field activities in remote areas.

- Allowing self monitoring and evaluation.

- Motivating PHMs to provide a quality service.

The following benefits were envisaged for MOH and other supervisory officers of the MOH office

- $\quad$ Easy monitoring and evaluation of field activities carried out by PHMs.

- Easy supervision

- Assisting in identifying health related problems in the $\mathrm{MOH}$ area 
- Facilitating planning of preventive care at $\mathrm{MOH}$ level

- Facilitating research activities

\section{Methods}

"e-Praja Suwa Arunalu" was started in the $\mathrm{MOH}$ area of Nivitigala in the Rathnapura District, situated in the Sabaragamuwa Province, approximately $100 \mathrm{~km}$ from Colombo. It is a rural area where there is a population of 65,000. There are $21 \mathrm{PHM}$ areas in this $\mathrm{MOH}$ area. Of them, five are vacant and were covered by five PHMs from adjacent areas. Therefore, in the study group there were only 16 PHMs. This project was mainly focused on a needs analysis, development, implementation and evaluation.

\section{Needs analysis}

Prior to the needs analysis, a literature survey was undertaken in order to assess the current situation of information management related to maternal and child health field activities. One important publication assessed the workload of PHMs in Sri Lanka. This was a study in 2008 by the Faculty of Medicine of the University of Colombo in collaboration with the Family Health Bureau of the Ministry of Health. The study collected opinions from 300 PHMs. In that assessment, $31 \%$ of PHMs perceived their workload as unbearably heavy, while $65 \%$ felt it was heavy. They attributed their heavy workload mainly to the large number of records and returns to be maintained (27\%), programmes and activities that were not directly related to health $(25 \%)$ and the large population to be served $(24 \%)^{(5,7)}$. The needs analysis was done using a questionnaire which obtained opinions from PHMs in the selected $\mathrm{MOH}$ area who were directly involved at grass roots level. Several informal interviews conducted with midwives were useful in formulating the questionnaire. The needs analysis clearly showed that PHMs spent most of their time on managing health records which might negatively affect their delivery of patient care. It also showed that insufficient attention had been given to increasing the quality of data they provided and to rapid dissemination of information. The information collected from the PHMs in the present study matched with results of the 2008 assessment described above. The information and knowledge gained from PHMs via the questionnaire and the interviews were useful in designing and developing the HIMS.

\section{Software development}

The system was designed according to the requirements of the users. The first version of the software was planned to be upgraded using iteration ${ }^{(8,9)}$. Data security was achieved by encryption of personal data. The interfaces were initially developed in English, but will be converted to Sinhalese and Tamil in the future.

\section{Training}

Training of the PHM staff was done in parallel with development and implementation. The PHMs were given Netbooks (mini-laptop computers) in order to maintain their documents in electronic format. Facilities were provided to print their registers and reports; when required.

\section{Monitoring and evaluation}

Proper monitoring and evaluation is essential for the improvement and continuity of health information systems ${ }^{(10,11)}$. Therefore, when the system was in operation the behaviour of the 
system and the users were monitored closely. At the same time regular discussions were conducted with users and they were provided with questionnaires in order to obtain their feedback and suggestions. Changes were applied to the software, depending on the responses. In other words, this study was conducted as Action Design Research and the iteration method was used to develop the system as the project proceeded $^{(8,9)}$.

\section{Results}

16 PHMs, who were trained for two months were involved in first evaluation which was conducted in October, 2011. Background information of PHMs and the view of the PHMs about the project are in Table 1 and Table 2. The results show that PHMs were highly satisfied with the system and they have learnt the basics of computer usage and the system without much difficulty. Furthermore, they started entering historical data from the registers into the system by themselves. This was an essential step before they could use the system for their field activities. Nearly 10,000 public health records were generated in the first three months.

\begin{tabular}{|l|l|c|c|}
\hline Variable & Category & Number & \% \\
\hline Age (years) & Under 35 & 7 & 44 \\
& $35-50$ & 4 & 25 \\
& Over 50 & 5 & 31 \\
\hline Civil status & Married & 15 & 94 \\
& Unmarried & 1 & 6 \\
\hline Education & Passed O/L*only & 3 & 19 \\
& Passed A/L* & 13 & 81 \\
\hline IT knowledge prior to project & Good & 7 & 12 \\
& Average & 7 & 44 \\
& Not at all & 2 & 44 \\
\hline Population in the service area & Less than 2000 & 3 & 12 \\
& 2000-4500 & 2 & 69 \\
& More than 4500 & 11 & 19 \\
\hline Size of the service area & Less than 1500 & 3 & 69 \\
(hectares) & $1500-5000$ & 3 \\
& More than 5000 & 12 \\
\hline
\end{tabular}

* $\mathrm{O} / \mathrm{L}$ - ordinary level school certificate, $\mathrm{A} / \mathrm{L}$ - advanced level school certificate

Table 1. Background information about the PHMs in the study group $(n=16)$

\section{Discussion}

Previous studies show that the public health of Sri Lanka is better than that of other South Asian countries ${ }^{(3,12)}$. However, public health information is still managed using a manual system which was introduced a long time ago. This is not very efficient and the manual system is time consuming. Therefore, introducing a computerised information system to manage public health information has become a necessity.

During the short period since implementation the pilot system has given satisfactory results, and this has encouraged all the participants. The survey showed that PHMs were happy with the pilot system and that they would like to continue using it to enhance their service. There are several reasons for this. The system was designed to provide a solution to a major 
problem in their field work. The PHMs could understand the workings at the database (backend) as they were educated about the data flow as well as on necessary statistical procedures which otherwise need to be done manually. They were also familiar with the interfaces as the computerised HIMS was a direct automation of the previous manual data management system.

\begin{tabular}{|l|l|l|l|l|}
\hline Question & Yes & $\%$ & No & $\%$ \\
\hline $\begin{array}{l}\text { 1. Are you happy with the system including the software, } \\
\text { interfaces and the way it is implemented? }\end{array}$ & 16 & 100 & 0 & 0 \\
\hline $\begin{array}{l}\text { 2. Do you feel that the system will be useful for your } \\
\text { activities in the field and would you like to continue using } \\
\text { it? }\end{array}$ & 16 & 100 & 0 & 0 \\
\hline $\begin{array}{l}\text { 3. Has your knowledge in computer use expanded } \\
\text { considerably in a short duration? }\end{array}$ & 16 & 100 & 0 & 0 \\
\hline $\begin{array}{l}\text { 4. Are you familiar with the basic interfaces of the } \\
\text { software? }\end{array}$ & 14 & 88 & 2 & 12 \\
\hline $\begin{array}{l}\text { 5. Have you already entered at least 50\% of past data into } \\
\text { the system? }\end{array}$ & 11 & 69 & 5 & 31 \\
\hline $\begin{array}{l}\text { 6. Are you ready to use this system for field activities? } \\
\text { 7. Are you planning to use this system to improve your }\end{array}$ & 13 & 81 & 3 & 19 \\
\hline service and to evaluate yourself? & 100 & 0 & 0 \\
\hline $\begin{array}{l}\text { 8. Are you satisfied with the training and support given by } \\
\text { the investigators? }\end{array}$ & 16 & 100 & 0 & 0 \\
\hline $\begin{array}{l}\text { 9. Are you satisfied with the modification process which } \\
\text { happens in response to your requests? }\end{array}$ & 16 & 100 & 0 & 0 \\
\hline $\begin{array}{l}\text { 10. Do you feel that you are actively involved in the } \\
\text { development process of the system? }\end{array}$ & 16 & 100 & 0 & 0 \\
\hline $\begin{array}{l}\text { 11. Would you like the project to be expanded to the rest of } \\
\text { the region in the near future? }\end{array}$ & 16 & 100 & 0 & 0 \\
\hline $\begin{array}{l}\text { 12. Do you think that being involved in this project has } \\
\text { badly affected other routine duties? }\end{array}$ & 0 & 0 & 16 & 100 \\
\hline $\begin{array}{l}\text { 13. Are you happy if your work is supervised by your } \\
\text { superiors through this system? }\end{array}$ & 13 & 81 & 3 & 19 \\
\hline $\begin{array}{l}\text { 14. Do you think that more time (3 or more months) is } \\
\text { needed for an effective evaluation of this project? }\end{array}$ & 16 & 100 & 0 & 0 \\
\hline
\end{tabular}

Table 2. Views of the PHMs about the project $(n=16)$

A major drawback in the project was the cost of implementation. It was relatively high. However, when long term benefits are considered, it would be a good investment to improve preventive healthcare. 
In conclusion, the results of the pilot study showed a high level of satisfaction by the users of the system. The PHMs found the system to be useful in their field work. In particular, they thought that their daily work had become easier. This is presumably one of the main reasons for the high level of acceptance. In addition, the PHMs believed that the system was userfriendly and easy to understand. Thus, the system is a practical solution to enhance the field activities of PHMs in Sri Lanka. However, further work needs to be done to study the long term benefits. The knowledge gained from this study would be useful for future e-Health implementations in the public health sector of Sri Lanka.

\section{Acknowledgement}

The Netbooks used for this project were provided by Intel.

\section{References}

1. O'Carroll PW, Yasnoff WA, Ward ME, Ripp LH, Martin EL. Introduction to public health informatics. Public Health Informatics and Information Systems. Hannah KJ, Ball MJ (eds). New York: Springer, 2003; 3-15. doi: http://dx.doi.org/10.1007/0-387-22745-8_1

2. Pappaioanou M, Malison M, Wilkins K, Otto B, Goodman RA, et al. Strengthening capacity in developing countries for evidence-based public health: the data for decisionmaking project. Social Science and Medicine 2003; 57:1925-37. doi: http://dx.doi.org/10.1016/S0277-9536(03)00058-3

3. AbouZahr C, Boerma T. Health information systems: the foundations of public health. Bull World Health Organ 2005; 83:578-83.

4. Bowen S, Zwi AB. Pathways to "evidence-informed" policy and practice: a framework for action. PLoS Medicine 2005; 2: e166.

doi: http://dx.doi.org/10.1371/journal.pmed.0020166

5. Health System Research Unit, Faculty of Medicine, University of Colombo. Assessment of Workload of Public Health Midwives in Sri Lanka. Colombo: Family Health Bureau Ministry of Health; 2008.

6. De Silva D. Health Progress in Ceylon: a Survey. Colombo: Government Press, 1956

7. Gunathunga M. Study of work performance and training of public health midwives of the western province of Sri Lanka. (MD thesis) Sri Lanka: University of Colombo, Department of Community Medicine. 1997.

8. Sommerville I. Software Engineering. Harlow, $8^{\text {th }}$ ed. Pearson Education, 2007.

9. Sein MK, Henfridsson O, Purao S, Rossi M, Lindgren R. Action design research. MIS Quarterly 2011; 35(1): 37-56. 
10. Mäenpää T, Suominen T, Asikainen P, Maass M, Rostila I. The outcomes of regional healthcare information systems in health care: a review of the research literature. International Journal of Medical Informatics 2009;78: 757-71.

doi: http://dx.doi.org/10.1016/j.ijmedinf.2009.07.001

11. Singh AK, Moidu K, Trell E, Wigertz O. Impact on the management and delivery of primary health care by a computer-based information system. Compute Methods and Programs in Biomedicine 1992;37:55-64.

doi: http://dx.doi.org/10.1016/0169-2607(92)90029-7

12. Ministry of Healthcare and Nutrition. Annual Health Statistics. Colombo: Ministry of Health Care and Nutrition, 2007. 